American Journal of Pharmaceutical Education 2018; 82 (9) Article 6403.

\title{
RESEARCH
}

\section{Nanotechnology Inclusion in Pharmaceutical Sciences Education in Portugal}

\author{
José das Neves, $\mathrm{PhD}$, PharmD \\ Instituto de Investigação e Inovação em Saúde (i3S) and Instituto de Engenharia Biomédica (INEB), University of Porto, \\ Porto, Portugal
}

Submitted March 14, 2017; accepted June 29, 2017; published November 2018.

\begin{abstract}
Objective. To analyze the inclusion of nanotechnology in the curricula of Integrated Master's in Pharmaceutical Sciences programs in Portugal.

Methods. Information regarding curricula (general notice and curricular unit description, objectives and syllabus) from national institutions was collected from their official websites or requested by e-mail, and analyzed for the occurrence of nanotechnology and related terms. A nanotechnology inclusion in curriculum (NIC) index was developed and used to rank each institution.

Results. All institutions with available data (eight out of nine) offered nanotechnology in their curricula. Both basic and applied nanotechnology-related education were offered to students but mostly from a theoretical perspective. The NIC index provided a standardized tool for comparing the institutions' programs and highlighted differences according to the relative importance of the presence of nanotechnology and related terms in curricula.

Conclusion. Portuguese institutions offering integrated master's programs in pharmaceutical sciences are including nanotechnology in their curricula. However, its implementation across all institutions remains weak and requires further strengthening to meet the requirements of this emerging field in health care practice.
\end{abstract}

Keywords: curricular unit, nanomedicine, nanoscience, pharmacist, pharmacy education

\section{INTRODUCTION}

The use of nanotechnology in pharmacy and medicine has been opening new and exciting avenues for the prevention, therapeutics and diagnostics of multiple diseases. ${ }^{1,2}$ Contrary to what could be perceived as a novel field with relatively limited practical value, many nanotechnology-based medical products are finding their way into the market while others have been already used in daily clinical practice for several decades, with applications in drug delivery, vaccines, medical imaging, diagnostics, medical devices or tissue engineering, and regenerative medicine. ${ }^{3-8}$ Indeed, it is expected that the approval of new nanotechnology-based medical products will grow exponentially over the next few years. ${ }^{9,10}$ Current and future pharmacists, alongside doctors and other health care providers, are expected to be acquainted with basic knowledge and key concepts of nanotechnology, particularly those related with medical applications, to face professional demands and challenges.

Corresponding Author: José das Neves, PhD, PharmD, Instituto de Investigação e Inovação em Saúde, Rua Alfredo Allen 208, 4200-135 Porto, Portugal. E-mail: j.dasneves@ineb. up.pt
Recommendations that undergraduate curricula leading to the Doctor of Pharmacy (PharmD) or equivalent degrees should include nanotechnology as a relevant subject are not new and have been directly or implicitly endorsed by worldwide education policy bodies such as the American Association of Colleges of Pharmacy (AACP) and the European Centre for the Development of Vocational Training (CEDEFOP). ${ }^{11-13}$ Limited data indicate that PharmD students are interested in nanotechnology but lack knowledge about it. ${ }^{14,15}$ Curricula in undergraduate pharmaceutical sciences education should be flexible and dynamic to allow incorporating scientific advances as these become increasingly important in health care. This not only allows preparing professionals better for the job market but also creates new career opportunities. ${ }^{16}$ Despite the increasing recognition of nanotechnology as an important topic in the pharmaceutical sciences, its inclusion in undergraduate curricula is poorly documented at the international and national levels. Qualitative and quantitative data are needed to better identify gaps and define strategies that can help students and faculties fulfill the demands for nanotechnology education.

The Portuguese system of higher education is well established, specifically with undergraduate education for candidates seeking to work as pharmacists. After 


\section{American Journal of Pharmaceutical Education 2018; 82 (9) Article 6403.}

finishing secondary/high school, students are required to obtain an Integrated Master's in Pharmaceutical Sciences (IMPS) degree (Level 7 education program according to the 2011 International Standard Classification of Education ${ }^{17}$ and equivalent to PharmD in the U.S.), and to register with the National Pharmacists Order (in Portuguese: Ordem dos Farmacêuticos), prior to practice. Nine higher education institutions are legally certified as able to confer the IMPS degree, offering comparable programs that comply with the Bologna Process ${ }^{18}$ and legal requirements from the European Union. ${ }^{19,20}$ The Portuguese setting can be regarded as a good standard of the post-Bologna Process era in European pharmacists' education. Programs have strong components in pharmaceutical, biomedical, physicochemical and biological sciences. Compared with the U.S. system, the degree confers both pharmacy practice and pharmaceutical sciences skills. The major pillars of pharmaceutical education curricula in Portugal have been well characterized ${ }^{21}$ but no specific information is available to the extent to which the subject of nanotechnology is being addressed at the undergraduate level. Thus, the objective of this study was to quantitatively assess and provide a critical appraisal of nanotechnology inclusion in the curricula of IMPS programs at Portuguese higher education institutions.

\section{METHODS}

Curricula from IMPS programs (second cycle degree) were obtained between December 2016 and February 2017 from the official webpages of public and private higher education institutions in Portugal (Table 1). When unavailable, information was requested by e-mail from general administrative offices. The following institu- tions are certified to confer the degree in pharmaceutical sciences: University of Algarve (UA), University of Beira Interior (UBI), University of Coimbra (UC), University of Lisbon (UL), University of Porto (UP), Instituto Universitário de Ciências da Saúde (IUCS), Instituto Superior de Ciências da Saúde Egas Moniz (ISCSEM), Fernando Pessoa University (FPU), and Lusófona University of Humanities and Technologies (LUHT).

References to nanotechnology or related terms in curricula were sought manually and automatically, and hits considered at different levels: the general notice of the IMPS program; curricular unit (course) name; and curricular unit description, objectives and syllabus. In this last case, references were considered as topics (ie, main theme or subject including further subheadings) or subtopics. Search terms in Portuguese and English associated with nanotechnology included those containing the prefixes "nano" or "bionano," "colloid," "dendrimer," "fleximer," "fullerene," "liposome," "micelle," "quantum dot" and "virosome." These are in line with criteria previously used in general and health care-related search strategies for literature pertaining to nanotechnology. ${ }^{22-24}$ Terms related with techniques used for the characterization of nanomaterials (eg, electron microscopy, spectroscopy) or typical properties of nanosystems (eg, zeta potential) were not considered unless specifically discussed in the framework of nanotechnology. Clear duplications of terms in the same curricular unit were considered as a single hit (eg, references for the same term in objectives and syllabus). Individual search hits were analyzed and terms clearly recognized as non-related to nanotechnology

Table 1. Portuguese Higher Education Institutions Offering Certified Integrated Master's Degree Programs in Pharmaceutical Sciences, according to Direção-Geral do Ensino Superior (Portuguese Directorate-General for Higher Education). ${ }^{27,28}$

\begin{tabular}{|c|c|c|c|c|c|}
\hline \multirow[b]{2}{*}{ Type } & \multirow[b]{2}{*}{ Institution } & \multirow[b]{2}{*}{ Website } & \multirow{2}{*}{$\begin{array}{c}\text { Registered } \\
\text { Students }^{\mathrm{a}} \text { N (\%) }\end{array}$} & \multicolumn{2}{|c|}{ ECTS Credits } \\
\hline & & & & Mandatory CUs & Optional CUs \\
\hline \multirow[t]{4}{*}{ Public } & University of Algarve (UA) & www.fct.ualg.pt & $178(3.8)$ & 288 & 12 \\
\hline & University of Coimbra (UC) & www.uc.pt/ffuc & $931(20.1)$ & 297 & 3 \\
\hline & University of Lisbon (UL) & www.ff.ul.pt & $1,240(26.8)$ & 288 & 12 \\
\hline & University of Porto (UP) & www.ff.up.pt & $1,001(21.6)$ & 268 & 32 \\
\hline & $\begin{array}{l}\text { Instituto Superior de Ciências da } \\
\text { Saúde Egas Moniz (ISCSEM) }\end{array}$ & www.egasmoniz.com.pt & $317(6.8)$ & 292 & 8 \\
\hline & $\begin{array}{l}\text { Instituto Universitário de Ciências } \\
\text { da Saúde (IUCS) }\end{array}$ & www.cespu.pt & $191(4.1)$ & 300 & 0 \\
\hline & $\begin{array}{l}\text { Lusófona University of Humanities } \\
\text { and Technologies (LUHT) }\end{array}$ & www.ulusofona.pt/ects & $213(4.6)$ & 290 & 10 \\
\hline
\end{tabular}

Abbreviations: CUs $=$ curricular units

${ }^{a}$ Data from academic year of 2014-2015; values in parentheses indicate percentage of total 


\section{American Journal of Pharmaceutical Education 2018; 82 (9) Article 6403.}

(eg, "nano" prefix as sub-unit of measurement, nanobacterium) were disregarded.

Data collected from curricula analysis were further used to calculate an index for assessing the nanotechnology inclusion in curriculum (NIC) of each program. References to nanotechnology or related terms were weighted differently according to the following equation:

$$
\text { NIC index }=a \cdot \sum_{i=1}^{n}\left(b_{i} \cdot c_{i} \cdot d_{i} \cdot e_{i}\right)
$$

where $a$ is the highest level for which at least one hit for nanotechnology or related terms was identified, $b$ the type of referencing (topic or subtopic) for each term at curricular units, $c$ the enforcement of the curricular unit in which terms were referenced, $d$ the number of European Credit Transfer and Accumulation System (ECTS) credits assigned to the curricular unit including nanotechnology or related terms, $e$ the type of classes in which the term appeared in, and $n$ the total number of hits for nanotechnology or related terms. Values for each factor considered in the calculation of the NIC index and their rationale are presented in Table $2 .^{25,26}$

Statistical analysis was performed using Student's $t$-test, namely for comparing mean hit and NIC index values for public and private institutions using GraphPad Prism 5.03 software (La Jolla, CA). Data were presented as mean (standard deviation) and values of $p<.05$ were accepted as denoting significance.

\section{RESULTS}

Basic information, such as general notice and overall structure, on IMPS programs, was available from the websites of all nine higher education institutions. Curricula encompassed mandatory and/or optional curricular units distributed throughout 10 semesters for a total of 300 ECTS credits. Completion of the first three years (180 ECTS credits) grants students a first cycle degree in Basic Studies of Pharmaceutical Sciences. Except for FPU and IUCS, the other institutions included optional courses in their curricula that can contribute from three to 32 ECTS credits (Table 1). The three largest and oldest institutions in Portugal, namely UC, UL and UP, accounted for over two-thirds of all registered students (3,172 out of $4,635)$ of IMPS programs according to the last available numbers (2014-2015 academic year). ${ }^{27,28}$ Detailed curricula were available online from seven institutions (UA, UBI, UC, UL, UP, IUCS and LUHT). Such information was solicited by e-mail from the two remaining institutions but only FPU provided the complete curriculum. Therefore, ISCSEM was excluded from the analysis at level 3.

No references to terms associated with nanotechnology were found at programs' general notice (level 1) or individual curricular unit designation (level 2) in all nine institutions. However, nanotechnology or other related terms were found 34 times (except for duplications) across all curricula when considering specific curricular unit description, objectives or syllabus. Eleven references

Table 2. Criteria and Values for Different Options Used to Establish the NIC Index

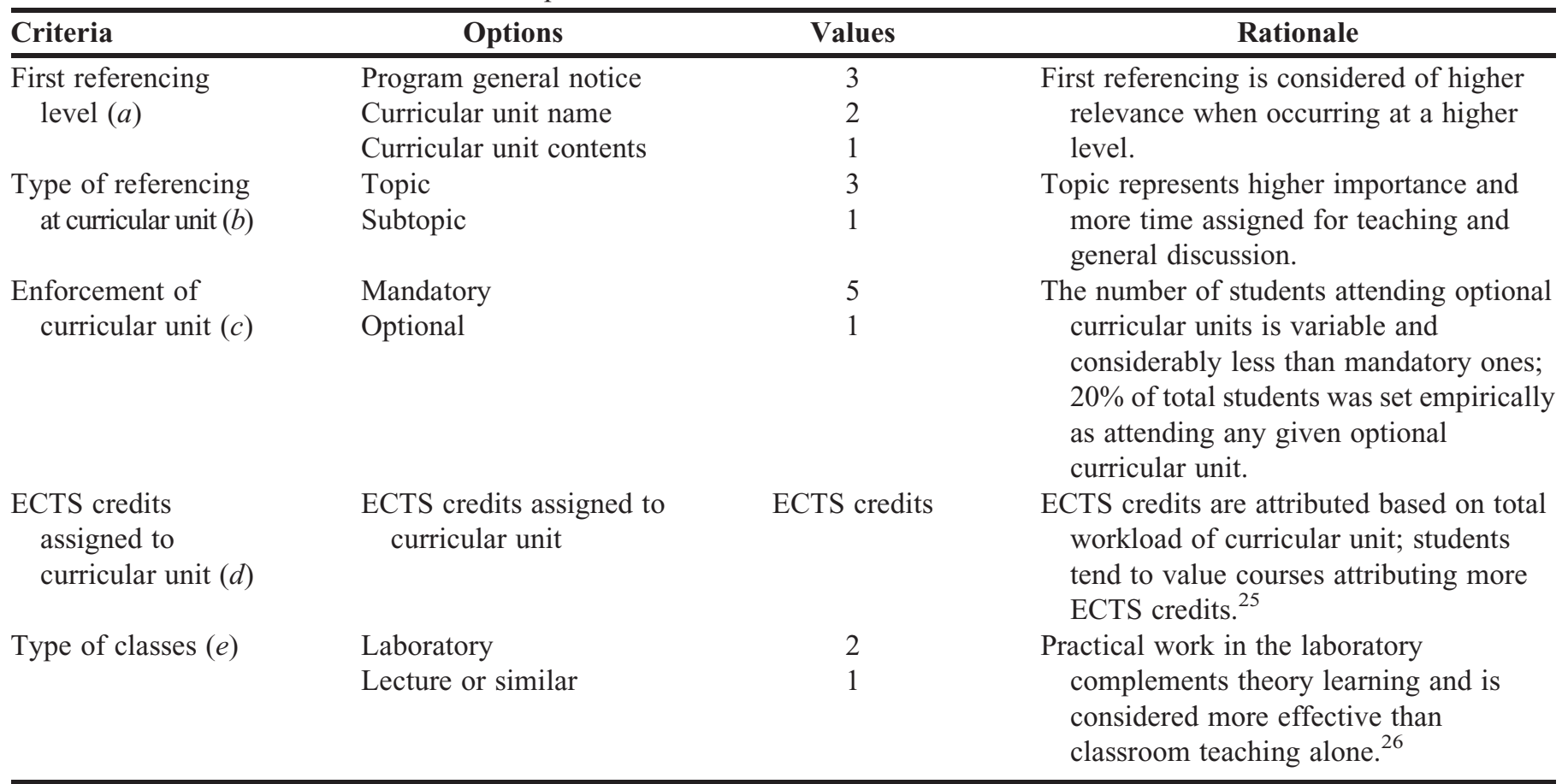




\section{American Journal of Pharmaceutical Education 2018; 82 (9) Article 6403.}

were registered for courses in the first six semesters (corresponding to the first cycle degree). Total hits per institution varied between one for UA and 11 for UP (Figure 1). Most terms were found as subtopics, although hits at the topic level were also found at UA, UL, UP, FPU and LUHT. Referencing to nanotechnology or related terms at the curricula from UP and FPU were highlighted from other institutions at the topic and subtopic levels, respectively. No significant differences were seen for mean total hits at both topic and subtopic levels when comparing public and private institutions.

Apart from the total number of references, it is important to consider which specific terms were mentioned in curricula. "Colloid" was the most frequent term among all contents of curricular units, followed by "micelle" and "nanoparticle," both with six occurrences (Figure 2). The terms "liposome," "nanoemulsion," "nanosystem/nanometric system" and "nanotechnology" were only mentioned twice overall, while single hits were registered for "dendrimer," "fullerene," "nanocrystal" and "nanostructured." Others such as "fleximer," "fullerene," "quantum dot" and "virosome" were not included in any of the curricula.

Nanotechnology-related terms were mostly referenced in curricular units of Pharmaceutical Technology (including Galenic Pharmacy), although a single course on New Therapeutic Systems from FPU contributed with roughly one-quarter of all hits. Applied Physics also contributed considerably to the total number of hits (Figure 3).

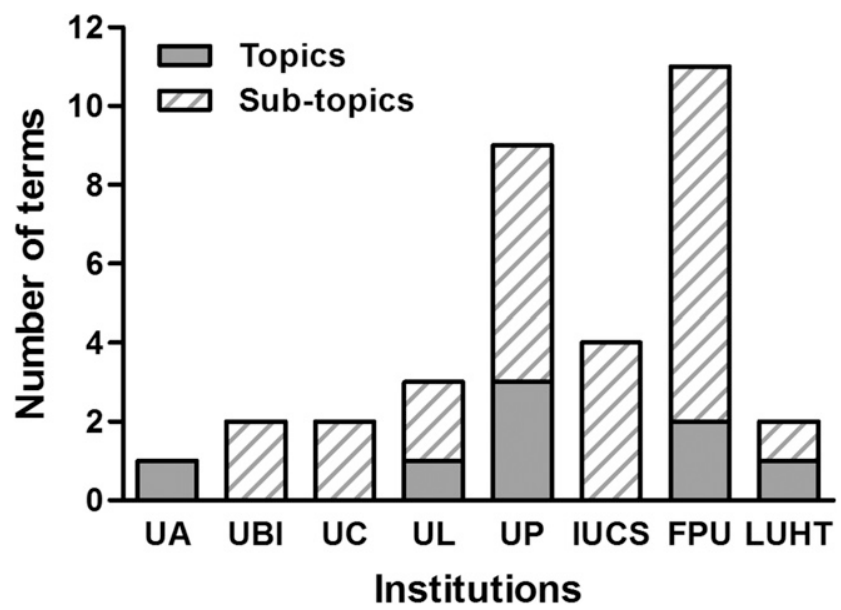

Figure 1. Number of Nanotechnology-related Terms Found in Curricula of Integrated Master's in Pharmaceutical Sciences Programs of Portuguese Higher Education Institutions, Either as Topics or Subtopics.

$\mathrm{UA}=$ University of Algarve, $\mathrm{UBI}=$ University of Beira Interior, $\mathrm{UC}=$ University of Coimbra, $\mathrm{UL}=$ University of Lisbon, $\mathrm{UP}=$ University of Porto, IUCS $=$ Instituto Universitário de Ciências da Saúde, FPU=Fernando Pessoa University, LUHT $=$ Lusófona University of Humanities and Technologies

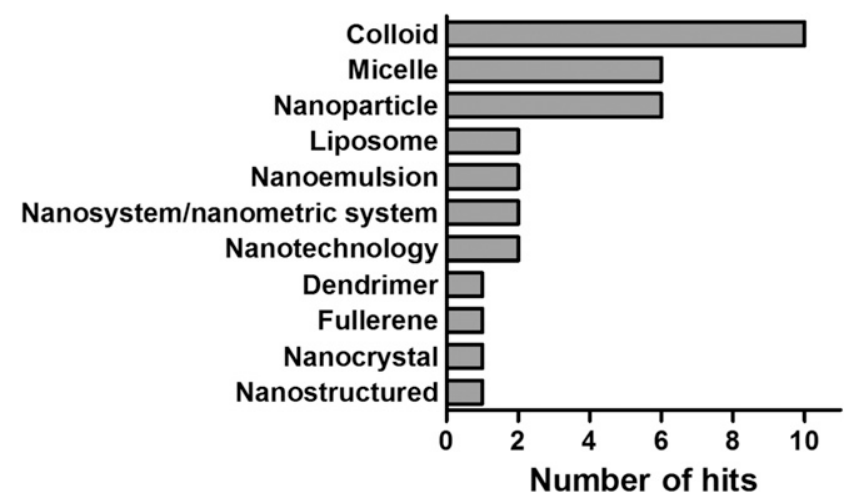

Figure 2. Number of Occurrences for Specific Nanotechnologyrelated Terms in Curricula of Integrated Master's in Pharmaceutical Sciences Programs of Portuguese Higher Education Institutions.

These three courses accounted for nearly $85 \%$ of all references to nanotechnology across curricula from the institutions included in the analysis. Other curricular units also encompassed discrete referencing to nanotechnology or related terms, namely Bioethics and Pharmaceutical Deontology (IUCS), Drug Delivery (LUHT), Physical Chemistry (LUHT) and Toxicology (UL). All hits considered in the curricula were in mandatory curricular units, except for one that was optional at UP. This included the preparation and assessment of diameter of nanostructured lipid carriers in laboratory classes of the Pharmaceutical Biotechnology \& Biomaterials course. Laboratory work encompassing the preparation of nanosystems was also included in two mandatory courses at FPU.

Results for the NIC index are shown in Figure 4. Values are in line with those for total references per institution (Figure 1). However, the NIC index tended to value programs of those institutions presenting higher amounts of topic hits. FPU presented the highest score

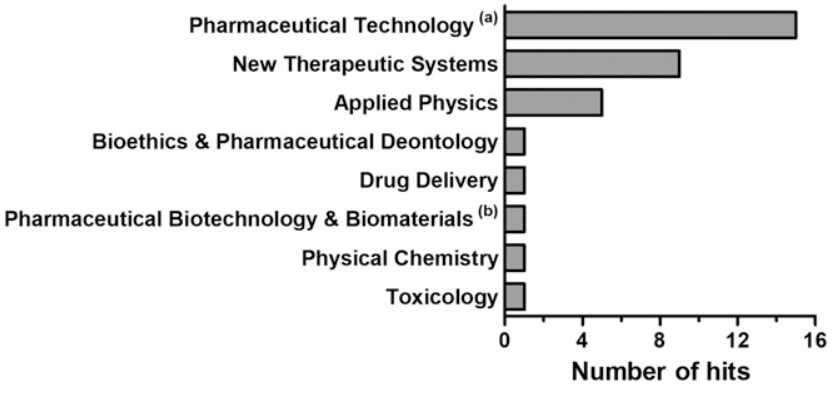

Figure 3. Number of Occurrences of Nanotechnology-related Terms per Specific Curricular Units in Curricula of Integrated Master's in Pharmaceutical Sciences Programs of Portuguese Higher Education Institutions.

a Includes Galenic Pharmacy

${ }^{\mathrm{b}}$ Optional curricular unit 


\section{American Journal of Pharmaceutical Education 2018; 82 (9) Article 6403.}

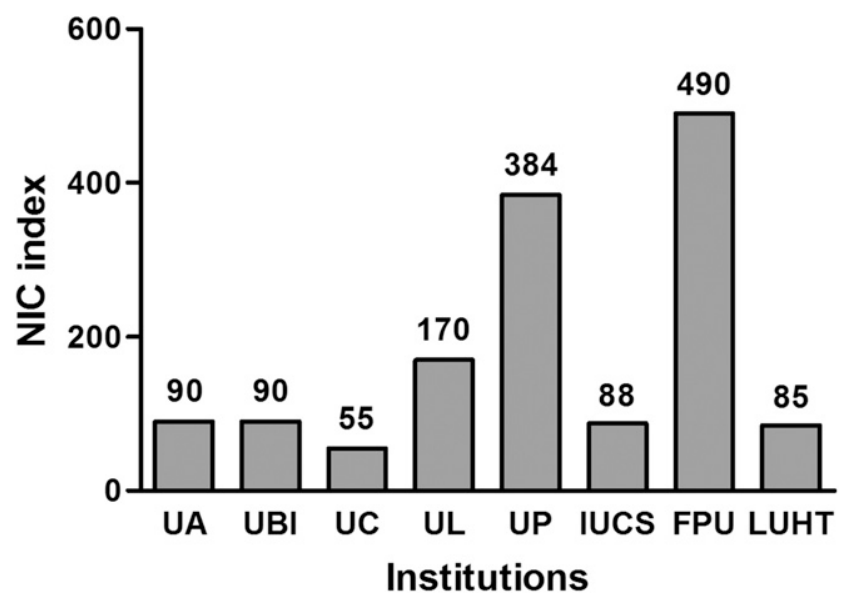

Figure 4. NIC Index Values for Curricula at Portuguese Higher Education Institutions Conferring the Degree of Integrated Master's in Pharmaceutical Sciences.

$\mathrm{UA}=$ University of Algarve, $\mathrm{UBI}=$ University of Beira Interior, $\mathrm{UC}=$ University of Coimbra, $\mathrm{UL}=$ University of Lisbon, $\mathrm{UP}=$ University of Porto, IUCS = Instituto Universitário de Ciências da Saúde, FPU=Fernando Pessoa University, LUHT $=$ Lusófona University of Humanities and Technologies

$($ NIC index $=490)$, followed by UP $($ NIC index $=384)$ and UL (NIC index $=170$ ). The remaining institutions presented similar scores, between 85 and 90, with the exception for $\mathrm{UC}$ that displayed the lowest value (NIC index $=55)$. No significant differences were observed for mean and standard deviation NIC indices of public 158 (133) and private 221 (233) institutions.

\section{DISCUSSION}

Nanotechnology products are streaming into the global society at a fast pace and revolutionizing everyday life in many ways. ${ }^{29}$ Health care is no exception as advances in pharmaceutical and biomedical nanotechnology have already provided important tools for preventing, diagnosing and treating diseases. Information regarding nanotechnology is abundant but not always readily available or easy to survey. Pharmacists are frequently required to handle, manage or provide information about nanotechnology-based products in their daily activities even if, often, without proper or conscious acknowledgement. Typical examples are products containing drug nanocrystals (eg, Emend, Rapamune) or drug-loaded liposomes (eg, AmBisome, Doxil), which are nanomedicines but are not readily recognized or labeled as such. Education on nanotechnology and its application to health care are of increasing importance because of market demand and the potentially harmful implications of nanomedicines to patient care. Hence, there is a need for nanotechnology inclusion in pharmacy education for students pursuing a PharmD or equivalent degree. However, extensive and objective data on the actual implementation of nanotechnology in pharmacy education worldwide are missing. Two studies on the status of pharmacy colleges in the U.S. indicate that the prevalence of nanotechnology courses at the undergraduate level is limited. ${ }^{30,31}$ For example, no specific courses on nanotechnology existed in the 106 curricula analyzed by Pathak and Koomer. ${ }^{30}$ Patel and colleagues showed that only four out of 127 PharmD curricula included specific optional courses on nanotechnology. ${ }^{31}$ However, both studies indicated that many institutions have already incorporated nanotechnology as a subject in curricular units, particularly in those related with pharmaceutics and drug delivery. These observations are in general agreement with those described for Portuguese institutions.

This study addresses the status of nanotechnology teaching in Portuguese higher education institutions that are certified to confer the IMPS. The methodological approach comprised a qualitative and quantitative analysis of references to nanotechnology from available curricular documentation. Similar strategies have been shown to be useful in the identification of specific contents or their gap in academic curricula, namely of undergraduate pharmacy programs and other higher education programs pertaining to health care professions. ${ }^{32-37}$ Results from the analysis of eight out of nine programs show that the topic of nanotechnology is at least partially taught in Portuguese institutions. Although the individual curricular unit description, objectives and syllabus offered at one private institution could not be scrutinized, the curricula analyzed in this study correspond to the contents provided to roughly $93 \%$ of students taking the IMPS in Portugal. The degree of inclusion of nanotechnology differed among institutions. FPU and UP consistently presented better scores for all evaluated parameters, while UA and $\mathrm{UC}$ were at the last positions regarding total hits and NIC index, respectively. While the number of references at each of the eight institutions was relatively low, these differences suggest the existence of considerable heterogeneity among the various curricula offered to pharmaceutical sciences students in Portugal. Noticeably, nanotechnology and its application to pharmacy and medicine was nearly absent from optional courses offered to students. This absence is interesting considering that controversial courses lacking basic scientific or clinical evidence, namely homeopathy, ${ }^{38}$ still encompass the role of optional curricular units at institutions such as UP.

The distinct occurrence of specific terms among curricula may further provide interesting indications as to different educational approaches to nanotechnology. The most frequently referenced term, "colloid," is often associated with fundamental principles in nanotechnology, which may indicate a strong teaching component 


\section{American Journal of Pharmaceutical Education 2018; 82 (9) Article 6403.}

of basic knowledge in curricula. The hit count for additional nanotechnology-related terms was heterogeneous. "Micelle" and "nanoparticle" accounted together for roughly $35 \%$ of total hits but, compared to "colloid," the basic or applied nature of their utility is not always easy to assess. One interesting observation was that of only two occurrences for "liposome." Liposomal systems are among the most well-established drug nanocarriers in clinical practice, including for the delivery of doxorubicin and amphotericin $\mathrm{B} .{ }^{39}$ The occurrence of a higher number of hits for "liposome" is expected for curricula with larger focus on nanotechnology, which reinforces the idea that a stronger inclusion of the subject is required.

Assessment of curricular units referencing nanotechnology complements the evaluation of basic or applied nature of nanotechnology teaching. The larger prevalence of nanotechnology-related terms at curricular units pertaining to pharmaceutical technology, as also described previously for pharmacy colleges in the U.S., ${ }^{30,31}$ indicates a focus on the application to the design of pharmaceutics. Moreover, one single curricular unit at FPU termed New Therapeutic Systems was responsible for a large number of hits because of its strong focus on nanotechnology applications to drug delivery. Two other observations should be highlighted. First, the nearly absent discussion in the context of pharmacology and toxicology is an important gap. Nanotechnology has been identified as a relevant topic responsible for introducing new paradigms into the field of pharmacology. ${ }^{40,41}$ In the case of toxicology, the concerns related to the possible harmful effects of nanomaterials on living organisms and the environment fully justify discussion of the subject. ${ }^{42}$ No references to nanotechnology were noted at any pharmacology courses. The only reference in the context of a toxicology curricular unit was observed at UL. Second, the ethical challenges of nanotechnology was approached in the curriculum at IUCS, providing a different yet relevant dimension to nanotechnology education. While most institutions offer the subject of ethical issues of general pharmacy practice in their curricula, specific subjects, particularly those in the cutting edge of the profession, should also be discussed.

The NIC index was proposed to provide a standardized evaluation of the relevance of nanotechnology in curricula. The principle behind this index relates to the actual or perceived different weight that individual hits of nanotechnology-related terms may have depending on type and place of occurrence. The NIC index intends to abbreviate possible bias originated by the simple summation of hits, particularly when absolute numbers are relatively low as in this study. Results for the NIC index of curricula offered by Portuguese institutions in this study are in general agreement with those for total hits of nanotechnology-related terms. Still, differences were observed, mostly related to the higher valorization of terms occurring as topics over subtopics. Favorable appraisal of programs at UA and UL was apparent when the NIC index was used, while the opposite happened for UC and IUCS.

This study has limitations. The absence of detailed information from one institution slightly shortened the analysis of the complete Portuguese panorama in pharmaceutical sciences education at the undergraduate level. As for the eight remaining programs that were assessed, the information for each curricular unit was not always complete or was described briefly and in broad topics. Some courses at UP also have restricted access to the complete contents. These issues could have reduced the total number of hits pertaining to nanotechnology. One particularly relevant case was that of the Drug Delivery curricular unit at LUHT, which included several broad topics on drug delivery systems. A book on nanotechnology and drug delivery was included in the recommended bibliography to students to assist in the discussion of nanotechnology at this curricular unit. Still, no hits were accounted according to the criteria proposed initially. Furthermore, curricular units comprising the development of a free project are available as mandatory or optional at several institutions (UBI, UC, UL and UP). Although no specific notice exists, projects can potentially be developed in the field of nanotechnology, even if only a minor fraction of students would likely be engaged in such a subject.

Another limitation is associated with the discrete time analysis of curricula. To the best of the author's knowledge, no similar study has ever been performed, thus making it impossible to assess the evolution of nanotechnology education over a defined interval. Iteration of this study in the future is suggested to provide such information. Regarding the proposed NIC index, criteria and relative weight are not immune to criticism. For example, items such as the involvement of faculty in research activities pertaining to nanotechnology or the specific time assigned to teaching nanotechnologyrelated topics during classes could also have been considered to increase ranking reliability. Still, assessment of such issues may not be easy to perform without conducting specific surveys. These last, however, may reduce the objectivity of the analysis since results can be typically influenced by individual prejudices or motivations of interviewees. $^{43}$

This study may help in establishing the relevance and integration of nanotechnology in curricula of IMPS programs in Portugal, and in creating a basis for future analysis and program changes. Beneficial actions to increase the inclusion of nanotechnology in PharmD curricula may 


\section{American Journal of Pharmaceutical Education 2018; 82 (9) Article 6403.}

include the following: requiring basic topics of nanotechnology in relevant courses, particularly those in pharmaceutical technology, toxicology and pharmacology, for all IMPS programs; creating new optional curricular units on nanotechnology; promoting parallel activities such as seminars, workshops and others on nanotechnologyrelated topics; and including nanotechnology in the general notice description of programs. This study may be useful for people and institutions recruiting professionals requiring a background on pharmaceutical and medical nanotechnology, and in selecting graduate students engaging in scientific projects in the field of nanotechnology applied to health care. This work may also help start the conversation around the current and future incorporation of nanotechnology as a relevant teaching subject in pharmacy education. The Portuguese pharmaceutical education system is considered a model of the post-Bologna Process era and could serve as a good case study for the European region. ${ }^{21}$ Hopefully, this study sparks analogous analysis and actions in other countries or regions worldwide.

\section{CONCLUSION}

Nanotechnology is an increasingly relevant issue in health care education and its delivery to prospective pharmacists is recognized as a necessity. This study presents the current status of nanotechnology inclusion in the curricula of Integrated Master's in Pharmaceutical Sciences in Portugal. Results showed that the occurrence of nanotechnology-related terms was generally mild and heterogeneous. Basic and applied nanotechnology education are taught even though laboratorial training is nearly nonexistent. The newly proposed NIC index may provide an interesting tool in assessing the inclusion of nanotechnology in curricula that could also be adapted to other subjects and curricular settings (eg, different curricula, graduate education). Still, some issues require further investigation, namely the evolution of the inclusion of nanotechnology in pharmaceutical sciences programs over time and the relevance of such analyses in future curricular changes.

\section{REFERENCES}

1. Farokhzad OC, Langer R. Impact of nanotechnology on drug delivery. ACS Nano. 2009;3(1):16-20.

2. Kim BY, Rutka JT, Chan WC. Nanomedicine. $N$ Engl J Med. 2010;363(25):2434-2443.

3. Weissig V, Pettinger TK, Murdock N. Nanopharmaceuticals (part 1): products on the market. Int J Nanomedicine. 2014;9:4357-4373.

4. van Riet E, Ainai A, Suzuki T, Kersten G, Hasegawa H. Combatting infectious diseases; nanotechnology as a platform for rational vaccine design. Adv Drug Deliv Rev. 2014;74:28-34.

5. Toy R, Bauer L, Hoimes C, Ghaghada KB, Karathanasis E. Targeted nanotechnology for cancer imaging. Adv Drug Deliv Rev. 2014;76:79-97.
6. Savaliya R, Shah D, Singh R, et al. Nanotechnology in disease diagnostic techniques. Curr Drug Metabol. 2015;16(8):645-661. 7. Habib-Ullah S, Fei D, Ge Y. Nanotechnology in advanced medical devices. In: Ge Y, Li S, Wang S, Moore R, eds. Nanomedicine. New York, NY: Springer; 2014:145-169.

8. Kim ES, Ahn EH, Dvir T, Kim DH. Emerging nanotechnology approaches in tissue engineering and regenerative medicine. Int $J$ Nanomedicine. 2014;9 Suppl 1:1-5.

9. Devalapally H, Chakilam A, Amiji MM. Role of nanotechnology in pharmaceutical product development. J Pharm Sci. 2007;96 (10):2547-2565.

10. James K, Highsmith J, Evers P. Nanotechnology marketnanotechnology markets in healthcare \& medicine. Drug Dev Deliv. 2014;11(12):43-45.

11. Roche VF, Nahata MC, Wells BG, et al. Roadmap to 2015: preparing competent pharmacists and pharmacy faculty for the future. Combined report of the 2005-06 Argus Commission and the academic affairs, professional affairs, and research and graduate affairs committees. Am J Pharm Educ. 2006;70(Suppl):Article S5.

12. Wells BG, Beck DE, Draugalis JR, et al. Report of the 2007-2008 Argus Commission: what future awaits beyond pharmaceutical care? Am J Pharm Educ. 2008;72(Suppl):Article S8.

13. Abicht L, Freikamp H, Schumann U. Identification of Skill Needs in Nanotechnology. Luxembourg: Office for Official Publications of the European Communities; 2006.

14. Pillai G, Koomer A, Tran HT, Pathak YV. Perceptions of pharmacy students towards nanotechnology: responses to an elective in nanotechnology applications. Poster presented at: 111th Annual Meeting of the American Association of Colleges of Pharmacy, July 2010; Seattle, WA.

15. Elmarzugi NA, Keleb EI, Mohamed AT, et al. Awareness of Libyan students and academic staff members of nanotechnology. $J$ Appl Pharm Sci. 2014;4(6):110-114.

16. Bhise SB, Deshpande AM. Accreditation of pharmacy institutions: design of curriculum. Indian J Pharm Educ Res. 2014;48(4): $1-5$.

17. European Commission/EACEA/Eurydice. The Structure of the European Education Systems 2016/17: Schematic Diagrams. Eurydice Facts and Figures. Luxembourg: Publications Office of the European Union; 2016.

18. European Commission/EACEA/Eurydice. The European Higher Education Area in 2015: Bologna Process Implementation Report. Luxembourg: Publications Office of the European Union; 2015. 19. European Parliament, European Council. Directive 2005/36/EC of the European Parliament and of the Council of 7 September 2005 on the recognition of professional qualifications. Official $J$ Eur Union. 2005;L255:22-142.

20. European Parliament, European Council. Directive 2013/55/EU of the European Parliament and of the Council of 20 November 2013 amending Directive 2005/36/EC on the recognition of professional qualifications and Regulation (EU) No 1024/2012 on administrative cooperation through the Internal Market Information System ('the IMI Regulation'). Official J Eur Union. 2013;L354:132-170. 21. PHARMINE Consortium. Pharmacy Education \& Training in Portugal, 2010. http:/www.pharmine.org/wp-content/uploads/2014/05/ PHARMINE-WP7-survey-Portugal.pdf. Accessed February 8, 2017. 22. Mogoutov A, Kahane B. Data search strategy for science and technology emergence: a scalable and evolutionary query for nanotechnology tracking. Res Policy. 2007;36(6):893-903. 23. Arora SK, Porter AL, Youtie J, Shapira P. Capturing new developments in an emerging technology: an updated search strategy 


\section{American Journal of Pharmaceutical Education 2018; 82 (9) Article 6403.}

for identifying nanotechnology research outputs. Scientometrics. 2013;95(1):351-370.

24. Etheridge ML, Campbell SA, Erdman AG, Haynes CL, Wolf SM, McCullough J. The big picture on nanomedicine: the state of investigational and approved nanomedicine products. Nanomedicine. 2013;9(1):1-14.

25. de la Fuente J, Cardelle-Elawar M, Peralta FJ, Sanchez MD, Martinez-Vicente JM, Zapata L. Students' factors affecting undergraduates' perceptions of their teaching and learning process within ECTS experience. Front Psychol. 2011;2:28.

26. Matz RL, Rothman ED, Krajcik JS, Banaszak Holl MM. Concurrent enrollment in lecture and laboratory enhances student performance and retention. J Res Sci Teach. 2012;49(5):659-682. 27. Direção-Geral do Ensino Superior. Pesquisa de Cursos e Instituições. http://www.dges.gov.pt/pt/pesquisa_cursos_instituicoes. Accessed January 20, 2017.

28. Direção-Geral do Ensino Superior. Dados e Estatísticas de Cursos Superiores. http://infocursos.mec.pt. Accessed February 3, 2017.

29. Vance ME, Kuiken T, Vejerano EP, et al. Nanotechnology in the real world: redeveloping the nanomaterial consumer products inventory. Beilstein J Nanotechnol. 2015;6:1769-1780.

30. Pathak YV, Koomer A. Nanotechnology in pharmaceutical education in USA. Paper presented at: NSTI Nanotechnology Conference and Trade Show, June 2008; Boston, MA. 31. Patel G, Sneed KB, Pathak YV. Nanotechnology in PharmD curriculum: a survey of COP curriculums. Abstract presented at: 114th Annual Meeting of the American Associaton of Colleges of Pharmacy, July 2013; Chicago, IL.

32. Fox BI, Karcher RB, Flynn A, Mitchell S. Pharmacy informatics syllabi in doctor of pharmacy programs in the US. Am J Pharm Educ. 2008;72(4):Article 89.
33. Kapol N, Maitreemit P, Pongcharoensuk P, Armstrong EP. Evaluation of curricula content based on Thai pharmacy competency standards. Am J Pharm Educ. 2008;72(1):Article 9.

34. Durkin L. A review of assessment methods within didactic syllabi from a graduate school of pharmacy. Assess Update. 2015;27 (6):9-12.

35. Zamani J, Vogel S, Moore A, Lucas K. Analysis of exercise content in undergraduate osteopathic education - a content analysis of UK curricula. Int J Osteopath Med. 2007;10(4):97-103.

36. O'Donoghue G, Doody C, Cusack T. Physical activity and exercise promotion and prescription in undergraduate physiotherapy education: content analysis of Irish curricula. Physiotherapy. 2011;97 (2):145-153.

37. Stickley L, Sechrist D, Taylor L. Analysis of sex and gender content in allied health professions' curricula. J Allied Health. 2016;45(3):168-175.

38. Fisher P, Ernst E. Should doctors recommend homeopathy? BMJ. 2015;351:h3735.

39. Pattni BS, Chupin VV, Torchilin VP. New developments in liposomal drug delivery. Chem Rev. 2015;115(19):10938-10966. 40. Goyal RK, Bhise SB, Srinivasan BP, Rao CM, Sen T, Koneri R. Curriculum for pharmacology in pharmacy institutions in India: opportunities and challenges. Indian J Pharmacol. 2014;46(3): 241-245.

41. Owen A.. Special issue of BJP on nanomedicine. Br J Pharmacol. 2014;171(17):3961-3962.

42. Krug HF. Nanosafety research - are we on the right track? Angew Chem Int Ed Engl. 2014;53(46):12304-12319.

43. Potter J, Hepburn A. Qualitative interviews in psychology: problems and possibilities. Qual Res Psychol. 2005;2(4): 281-307. 